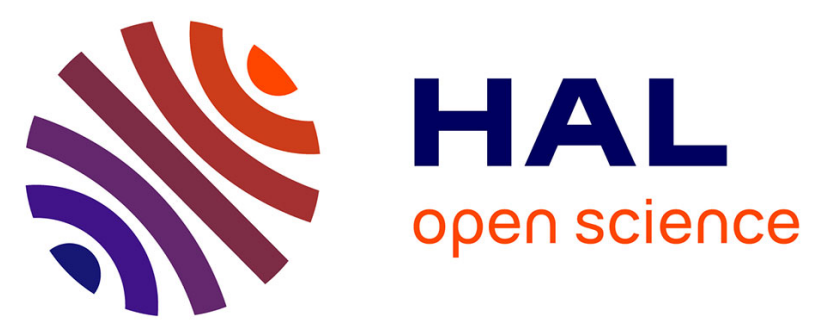

\title{
The global alignment in patients with lumbar spinal stenosis: our experience using the EOS full-body images
}

Jean-Yves Lazennec, Dominique Foliniais, Samy Bandaya, Marc-Antoine

Rousseau, Aidin Eslam Pour

\section{- To cite this version:}

Jean-Yves Lazennec, Dominique Foliniais, Samy Bandaya, Marc-Antoine Rousseau, Aidin Eslam Pour. The global alignment in patients with lumbar spinal stenosis: our experience using the EOS full-body images. European Journal of Orthopaedic Surgery \& Traumatology, 2016, 26, pp.713-24. 10.1007/s00590-016-1833-4 . hal-02481623

\section{HAL Id: hal-02481623 \\ https://hal.science/hal-02481623}

Submitted on 17 Feb 2020

HAL is a multi-disciplinary open access archive for the deposit and dissemination of scientific research documents, whether they are published or not. The documents may come from teaching and research institutions in France or abroad, or from public or private research centers.
L'archive ouverte pluridisciplinaire HAL, est destinée au dépôt et à la diffusion de documents scientifiques de niveau recherche, publiés ou non, émanant des établissements d'enseignement et de recherche français ou étrangers, des laboratoires publics ou privés. 


\title{
The global alignment in patients with lumbar spinal stenosis: our experience using the EOS full-body images
}

\author{
Jean Yves Lazennec ${ }^{1,2,3} \cdot$ Dominique Folinais $^{4} \cdot$ Samy Bendaya $^{5} \cdot$ \\ Marc Antoine Rousseau ${ }^{2,6} \cdot$ Aidin Eslam Pour ${ }^{7}$
}

\begin{abstract}
Lumbar stenosis is frequently observed and treated by spine surgeons. The extent of neurological decompression and the potential spinal fixation are the basic concerns when surgery is planned. But this segmented approach to the problem is sometimes insufficient due to the complex functional situations induced by a sagittal imbalance of the patient and the combination of pathologies known as hip-spine or knee-spine syndromes. A total of 373 consecutive patients included from our EOS and clinical data base. Patients were divided in two groups. Group A included patients presenting exclusive spinal issues (172 cases) out of whom $117(68 \%)$ had sagittal imbalance. Among 201 patients with associated lower limbs issues (group B), 122 (61\%) had sagittal imbalance. The perception of imbalance was noticed in $54 \%$ (93 cases) in group A and $57 \%$ (115 cases) in group B. In the global series of 239 imbalanced cases, the key point was a spine issue for 165 patients (the 117 patients with only
\end{abstract}

Jean Yves Lazennec

lazennec.jy@wanadoo.fr

1 Department of Orthopaedic and Trauma Surgery, PitiéSalpétrière hospital Assistance Publique - Hopitaux de Paris, UPMC, Paris, France

2 Biomechanics Lab (LBM), Arts et Metiers Paris-Tech, Paris, France

3 Department of Anatomy, UPMC, Paris, France

4 RIM Maussins-Nollet, 114 rue Nollet, 75017 Paris, France

5 Rothschild Hospital Assistance Publique - Hopitaux de Paris, Paris, France

6 Avicenne Hospital Assistance Publique - Hopitaux de Paris, Bobigny, France

7 Department of Orthopaedic Surgery, University of Michigan, Ann Arbor, MI, USA spine problems and 48/122 cases with combined spine and lower limbs problems). But in the patients with combined spine and lower limbs problems, we individualized hipspine syndromes (24/122 patients) and knee-spine syndromes (13/122 patients). In some cases, (37/122 patients) the anatomical and functional situations were more complex to characterize a spine-hip or a hip-spine problem. The EOS full-body images provide new information regarding the global spinal and lower limbs alignment to improve the understanding of the patient functional posture. This study highlights the importance of the lower limb evaluation not only as compensatory mechanism of the spinal problems but also as an individualized parameter with its own influence on the global balance analysis.

Level of evidence IV diagnostic case series.

Keywords Spinal stenosis - Spinal sagittal alignment . Spinal postural balance $\cdot$ EOS $\cdot$ Knee alignment $\cdot$ Hip-spine syndrome $\cdot$ Hip flexion $\cdot$ Knee-spine syndrome $\cdot$ Pelvic tilt . Global tilt - Spinopelvic parameters - Total hip prosthesis . Total knee prosthesis - Sitting position - Standing position . Knee flessum · Sagittal femoral tilt

\section{Introduction}

The global spine alignment has been a hot topic in recent years. The literature has focused on the definition of the normal sagittal alignment [1,2], the individualization of sagittal morphotypes [3] and the description of compensatory mechanisms in case of sagittal imbalance [4]. Despite a growing interest, the relationship between the spinal balance and the lower limbs remains less documented than the concept of pelvic vertebra [5] and the spinopelvic disorders $[6,7]$. The sagittal balance reference 
parameters have been initially described for young individuals without any spinal or lower limbs problems. But older and symptomatic patients may face other functional situations due to the overweight or associated impairments of the lower limbs [8-10]. Moreover, the frontal balance is often neglected in the classical series as well as the pelvic obliquity or the pelvic rotation.

The EOS imaging system provides new information regarding the global spinal and lower limbs alignment and highlights the importance of the full-body analysis to improve the understanding of the patient situation. Furthermore, the combined sitting acquisitions provide

Table 1 Clinical background

\begin{tabular}{ll}
\hline & $(n=373)$ \\
\hline Significant and permanent radiculopathy & 237 \\
Neurological claudication & 301 \\
Neurological claudication with walking ability $<100 \mathrm{~m}$ & 205 \\
Neurological claudication with walking $<10 \mathrm{~m}$ & 59 \\
Urodynamic signs & 39 \\
\hline
\end{tabular}

additional information about the reducibility of standing abnormalities. Some dynamic postural evaluations (bending tests, extension ability tests) can be used to complete the postural analysis. This paper is focused on the postural characteristics of the lumbar stenosis patients. This pathology is frequently observed and treated by spine surgeons. The extent of neurological decompression and the potential spinal fixation are the basic concerns when surgery is planned. But this segmented approach to the problem is sometimes insufficient due to the complex functional situations induced by a sagittal or frontal imbalance of the patient.

This is also highly represented in the hip and/or knee patients especially in the cases needing a joint replacement. This specific combination of pathologies induces sensitive situations known as hip-spine syndromes or kneespine syndromes [11-19]. The hierarchy of the surgical strategies is often discussed in such patients, but the misunderstanding or underrating of the problems may lead to catastrophic situations [20]. The aim of this report is to describe the profile of these patients in our common practice and to illustrate these issues using our clinical and EOS images data base.

Table 2 Clinical data

\begin{tabular}{ll}
\hline & $(n=373)$ \\
\hline Segmental lumbar stenosis (1 or 2 levels) & $205(55 \%)$ \\
Global lumbar stenosis & $159(43 \%)$ \\
Thoraco-lumbar stenosis & $9(2 \%)$ \\
Associated symptomatic cervical stenosis & $97(26 \%)$ \\
Patients with exclusive spinal pathology & $172(46 \%)$ \\
Patients with associated lower limbs issues & $201(54 \%)$ \\
Spondylolisthesis & $110(29.5 \%)$ \\
Degenerative spondylolisthesis & 93 \\
Isthmic spondylolisthesis & 17 \\
Previous segmental lumbar fusions $(1$ or 2 levels) & 37 \\
Previous long lumbar fusions $(>2$ levels or including thoraco-lumbar junction) & 15 \\
Patients with THA & $101(27 \%)$ \\
Patients with unilateral THA & 78 \\
Patients with bilateral THA & 23 \\
Patients with TKA & $64(17 \%)$ \\
Patients with unilateral TKA & 51 \\
Patients with bilateral TKA & 13 \\
Patients with previous femoral or tibial osteotomy & 11 \\
Limb length discrepancy (anatomical) & $85(23 \%)$ \\
Limb length discrepancy (functional) (flexum or recurvatum) & $194(52 \%)$ \\
Genu varum $>6^{\circ}$ & $118(32 \%)$ \\
Genu valgum $>6^{\circ}$ & 14 \\
Pelvic obliquity $\left(>10^{\circ}\right)$ & $55(15 \%)$ \\
Pelvic rotation $\left(>5^{\circ}\right)$ & $69(18 \%)$ \\
\hline
\end{tabular}




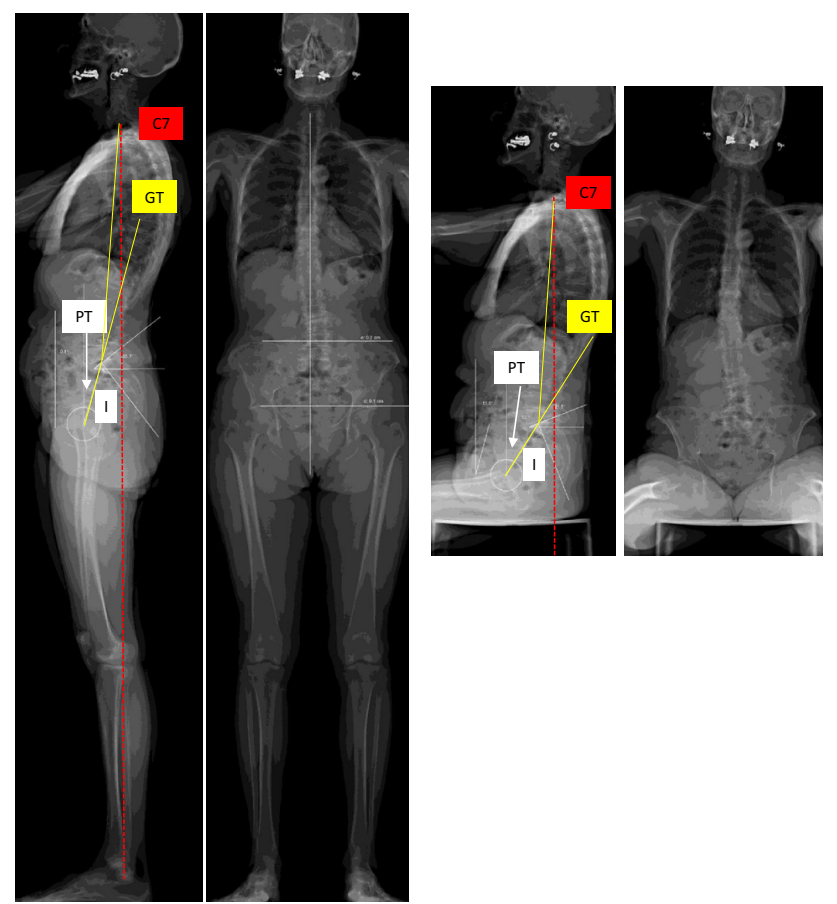

Fig. 1 Typical set of EOS images used for this study. The full-body view provides information about the lower limbs (anatomical particularities and functional adaptations). Sitting position is useful to assess the adaptation possibilities of spine and hips and to evaluate the modifications of sagittal balance

\section{Materials and methods}

We included 373 consecutive patients (137 men, 236 female) from our current practice EOS database. The mean age was 72 years (56-87), and mean BMI was $28.1 \pm 3.1$. All these patients were diagnosed with spinal stenosis. All of them were referred for a surgical procedure. We excluded posttraumatic spinal stenosis and patients with a significant frontal deformity (Cobb angle $>20^{\circ}$ ). We individualized the patients in two functional groups. Group A includes the patients with lumbar stenosis symptoms only; group B includes the patients with combined spinal stenosis and lower limbs impairments.

The clinical details of the series are given in Tables 1 and 2. Using the simultaneous AP and lateral EOS images, we measured the classical spinopelvic parameters to assess the sagittal balance condition [pelvic incidence (PI), sacral slope (SS), pelvic tilt (PT), C7 sagittal vertical axis (SVA), and global tilt (GT)] [21]. PT modifications were evaluated according to the incidence angle [22]. We also evaluated the lower limbs position (HKA angle, femoral sagittal tilt angle FST, knee flexion angle KFA, and sacro-femoral angle SFA) [22]. Pelvic frontal inclination was measured using the pelvic obliquity angle (POA) (angle between the horizontal line and the line through the femoral head centers) (Figs. 1,2).
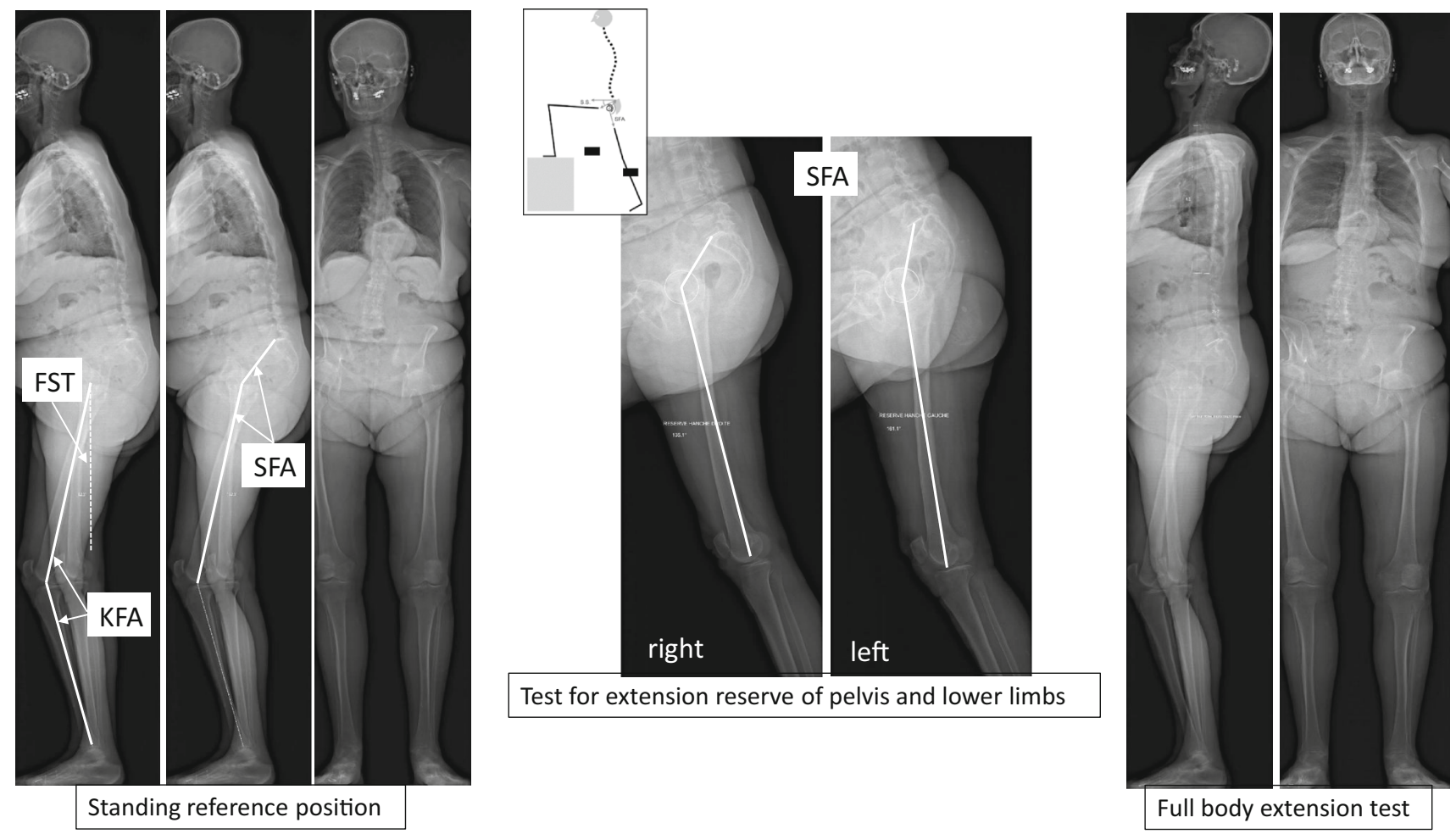

Fig. 2 Static and dynamic EOS tests to measure. The knee flexion angle KFA. The sacro-femoral angle SFA. The femoral sagittal tilt FST 
Fig. 3 Three types for sagittal balance evaluation
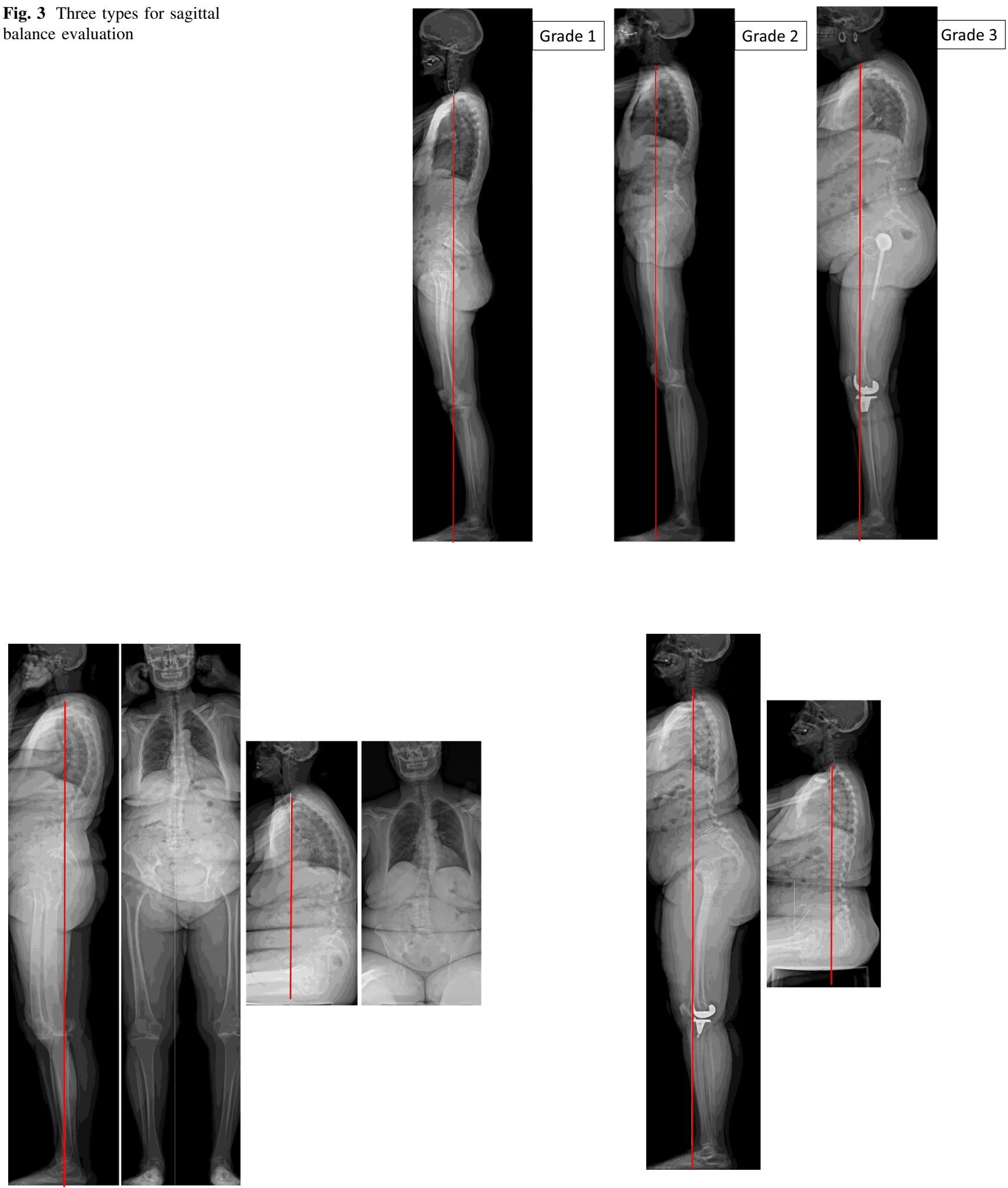

Fig. 4 Patient grade 1 in standing position. Despite this correct global balance, a significant pelvic rotation and frontal imbalance are observed. In sitting position the patient moves to grade 3
Fig. 5 Comparison of standing and sitting. Grade 3 in standing position; grade 2 in sitting position 

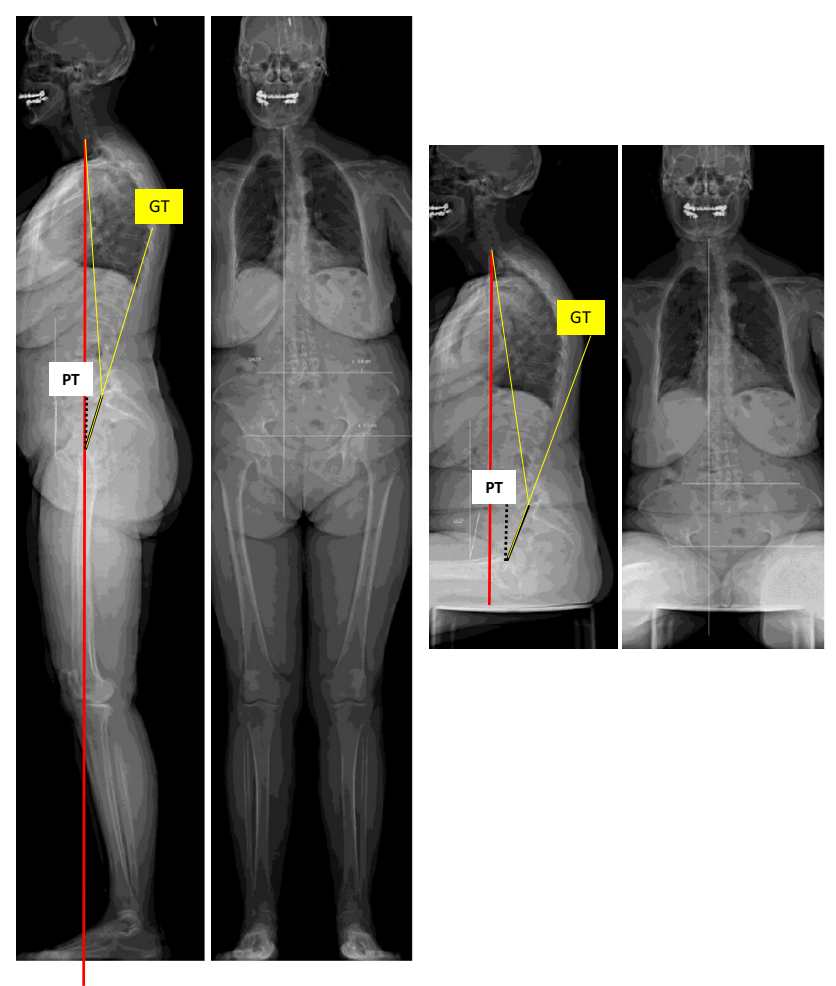

Fig. 6 Comparison of standing and sitting positions. Grade 2 in standing position; grade 3 in sitting position. The frontal imbalance is unchanged. PT is increased in sitting position (additional pelvic retroversion)

On a practical point of view, we divided the patients in three grades, based on their balance according to the literature: (grade 1) normal balance, C7 SVA over the sacral endplate; (grade 2) slight unbalance, C7 SVA located between sacral endplate and femoral heads; (grade 3) severe unbalance, C7 SVA located in front of the femoral heads [17] (Fig. 3). A significant adaptive adjustment of the lower limb position has been defined as mean KFA $>10^{\circ}$ and/or mean FST $>15^{\circ}$ (Fig. 4). Unilateral hip or knee flexum angle was analyzed separately. Sitting EOS imaging was performed in all patients to assess the participation of the lower limbs anatomy or posture in the global balance. We used the same grades 1, 2, and 3 to assess the sitting balance of the patients (Figs. 4, 5, 6). PT and GT in sitting position were compared with standing PT and GT (Figs. 7, 8, 9). Logistic regression was used to find any correlation between the patients' perception of the imbalance and objective measurements of the different parameters. The significance level was set at $5 \%$.

\section{Results}

The description of the series is reported in Tables 1, 2, $3,4,5$.

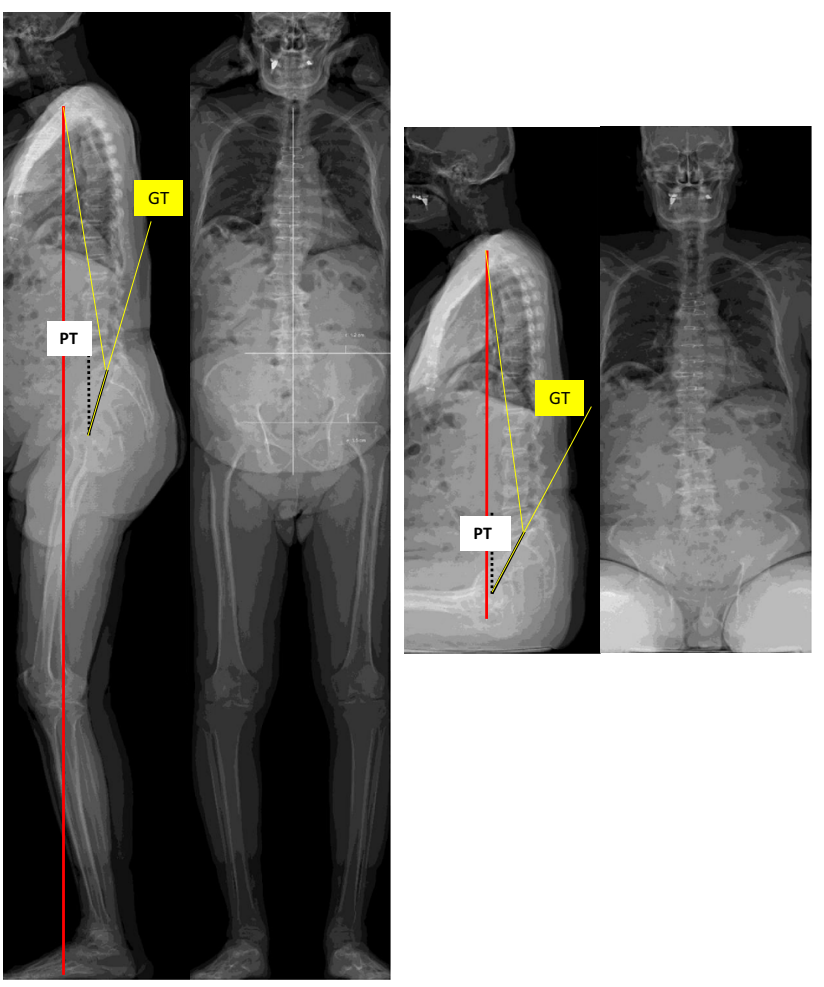

Fig. 7 Grade 3 patient with flat back in standing position. C7 SVA is anterior to the femoral heads. No significant frontal imbalance despite some pelvic obliquity on the AP view (genu varum on the right side). In sitting position the patient is grade 2 (moderate increase of PT and GT)

If we consider the global balance of the patients, $36 \%$ of the patients (134/373 cases) did not experience sagittal imbalance (grade 1), and $64 \%$ of the patients presented an imbalance problem (117 cases accounting for $68 \%$ in group A with spinal issues and 122 cases accounting for $61 \%$, in the group B with combined lower limbs problems). Grade 2 with a moderate imbalance represents $47.5 \%$ of the patients (177/373 cases), and $16.5 \%$ of the patients are grade 3 with a severe imbalance (62/373 cases).

In the group A, only $79 \%$ of patients with imbalance problems (93/117 cases) perceived the imbalance. This included all 21 cases grade 3 and only 62 of the 96 grade 2 patients. Out of 117 cases, 89 (76\%) demonstrated an adaptive adjustment of the lower limbs according to our criteria, but all the 117 cases demonstrated pelvic retroversion with an increase in PT values according to the literature [4].

In the group B with combined lower limbs problems, $94 \%$ of the patients with imbalance problems perceived the imbalance $(115 / 122$ cases). This included all the 41 patients of grade 3 and 64 of the 81 cases of grade 2. In all the 122 cases, PT was increased, but only 84 out of 122 cases $(69 \%)$ demonstrated an adaptive adjustment of the lower limbs according to our criteria's. 


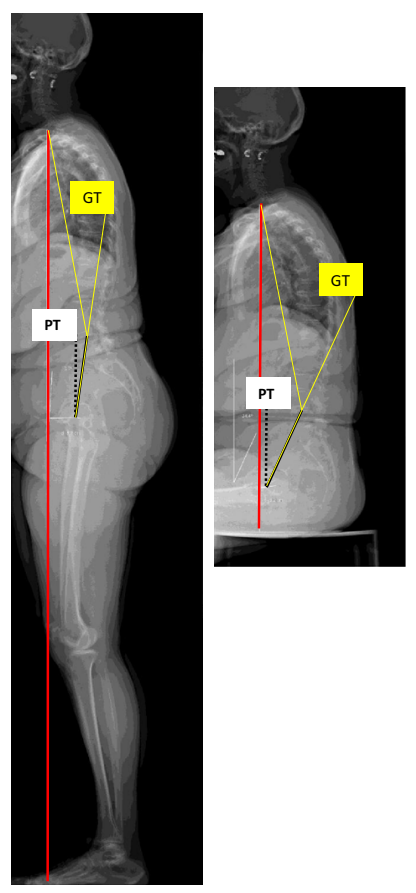

Fig. 8 Grade 3 patient in standing position. No adaptation of the lower limbs despite a C7 SVA $50 \mathrm{~mm}$ anterior to the femoral heads. The comparison with sitting position (grade 2) shows some additional pelvic retroversion (PT increase). GT significantly increases for sitting position

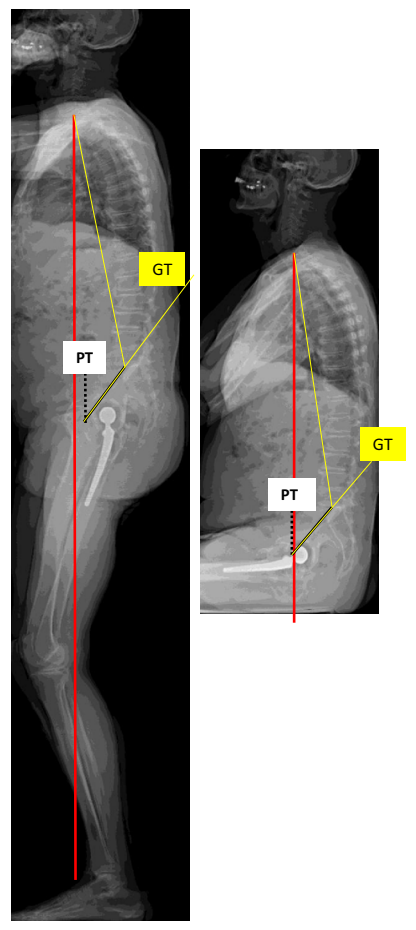

Fig. 9 Grade 3 patient in standing position (hips and knees adaptive flexion). Grade 2 in seated position, very moderate increase in PT and GT. No significant modification of spine orientation: the patient is mainly a hip user for sitting
Table 3 Geometric parameters in standing position

\begin{tabular}{lcc}
\hline Variable & Mean & SD \\
\hline Sacral slope standing $\left(^{\circ}\right)$ & 29.3 & 11.6 \\
Pelvic incidence $\left(^{\circ}\right)$ & 55.8 & 14.7 \\
Pelvic tilt $\left(^{\circ}\right)$ & 24.3 & 12.34 \\
Pelvic obliquity angle $\left(^{\circ}\right)$ & 6.1 & 11.61 \\
SVA (mm) & 92.2 & 6.1 \\
GT $\left(^{\circ}\right)$ & 49.4 & 18.1 \\
FST $\left({ }^{\circ}\right)$ & $12.5^{\circ}$ & $9.1^{\circ}$ \\
KFA $\left(^{\circ}\right)$ & $17.4^{\circ}$ & $9.3^{\circ}$ \\
HKA angle $\left(^{\circ}\right)$ & $5.8^{\circ}$ & $7.4^{\circ}$ \\
\hline
\end{tabular}

In either groups $\mathrm{A}$ and $\mathrm{B}$, the perception of the sagittal balance is systematically perceived in grade 3 patients. In grade 2 patients, the parameters related to the perception of imbalance were SVA $(p=0.014)$, low incidence angle $(p=0.02), \quad$ GT $>25 \quad(p=0.04), \quad$ PT increase $>15^{\circ}$ $(p=0.018)$, knee varus $>6^{\circ}(p=0.035)$, limb length discrepancy $>1 \mathrm{~cm}(p=0.015)$, bilateral knee flexum $>15^{\circ}(p=0.04)$, bilateral FST $>20^{\circ}(p=0.037)$, unilateral hip flexum $>20^{\circ}(p=0.017)$, unilateral knee flexum $>15^{\circ}(0.02), \quad \mathrm{POA}>10^{\circ}(p=0.029)$ and associated symptomatic cervical spinal stenosis $(p=0.031)$.

Comparison between standing and sitting EOS images is reported in Table 5. Most of the cases were grade 2 in sitting position. Most of the cases of grade 1 and 3 shifted to grade 2 . Few cases remained in grade 3 with severe imbalance due to a stiff spine pelvic area. In group A, patients with imbalance (117 cases), an adaptive lower limbs adjustment is observed in 89 patients in standing position. Sixty of these 89 cases had an additional PT increase for sitting position (mean $10^{\circ}$ ). In the group B patients with imbalance and combined lower limbs problems (122 cases), 84 cases had an adaptive adjustment of the lower limbs. Seventy-six of the 84 cases had an additional PT increase in sitting position (mean $8^{\circ}$ ).

\section{Discussion}

This study highlights several points regarding the spinal balance in this very specific population of spinal stenosis patients. At first, an associated lower limbs issue is observed in 201 patients (54\% of the whole series). This high percentage points out the importance of the global evaluation of the patient: the spine evaluation cannot be performed without a careful analysis of the lower limbs (Figs. 10, 11) [22]. The key points for sagittal balance analysis in spinal stenosis patients are the detection of 
Table 4 Sagittal balance evaluation $(n=373)$

\begin{tabular}{ll}
\hline Grade 1 & $134(36 \%)$ \\
Grade 2 & $177(47.5 \%)$ \\
Grade 3 & $62(16.5 \%)$
\end{tabular}

Patients with exclusive spinal issues (Group A): 172

- Patients with no sagittal imbalance (all grade 1): 55 (32\%)

- Patients with sagittal imbalance: 117 (68\%)

Grade 2: 96

Grade 3: 21

○ Patients perceiving the imbalance: 93 (54\%)

Grade 2: 62

Grade 3: 21

- Patients with sagittal imbalance and adaptive adjustment of the lower limbs: 89/117 cases

- Associated segmental instability: 44/172 cases (25\%)

Patients with associated lower limbs issues (Group B): 201

○ Patients with no sagittal imbalance (all grade 1): 79 (39\%)

- Patients with sagittal imbalance: 122 (61\%)

Grade 2: 81

Grade 3: 41

- Patients perceiving the imbalance: 115 (57\%)

Grade 2: 64

Grade 3: 41

- Patients with sagittal imbalance and typical adaptive adjustment of the lower limbs: 84

$\checkmark$ Imbalance is due to spine problems: 48 (grade 2: 41 cases; grade 3: 7 cases)

$\checkmark$ Imbalance is due to hip problems: 24 (grade 2: 16 cases; grade 3: 8 cases)

$\checkmark$ Imbalance is due to knee problems: 13 (grade 2: 5 cases; grade 3: 8 cases)

$\checkmark$ Imbalance is due to associated spine and hip problems: 28 (grade 2: 16 cases; grade 3: 12 cases)

Imbalance is due to associated spine and knee problems: 7 (grade 2: 3 cases; grade 3: 4 cases)

Imbalance is due to associated spine, hip and knee problems: 2 (grade 2: 0 cases; grade 3: 2 cases)

- Associated segmental instability: 76/201 cases (38\%)
Table 5 Comparison of standing and sitting balance patterns

\begin{tabular}{lll}
\hline$(n=373)$ & Standing & Sitting \\
\hline Grade 1 & $134(36 \%)$ & $53(14 \%)$ \\
Grade 2 & $177(47.5 \%)$ & $309(83 \%)$ \\
Grade 3 & $62(16.5 \%)$ & $11(3 \%)$ \\
Pelvic tilt (PT) & Mean 24.3 (SD 12.34) & Mean 36 (SD 12.8) \\
Global tilt (GT) & Mean 49.4 (SD 18.1) & Mean 59.1 (SD 10.7) \\
\hline
\end{tabular}

imbalance, the appreciation of its severity, and the diagnosis of combined problems involving the lower limbs.

The recent literature describes multiple geometrical parameters for the evaluation of the sagittal mal-alignments and the imbalance compensatory mechanisms. But this evaluation is complex to use in current practice. The individualization of the grade 2 and 3 cases for imbalance is easy to apply, while measuring the SVA distance does not give such a practical appreciation (the same SVA does not have the same significance according to the incidence angle).

PT change must be analyzed according to the patient's incidence angle as previously described: the significance of $10^{\circ}$ increase (pelvic retroversion) is different for patients with low and high incidence angle according to Barrey et al. data [4]. Such a $10^{\circ}$ increase doubles the normal PT value for patients with incidence angle $<48^{\circ}$. On the contrary, it is only a PT $60 \%$ increase if the incidence is $58^{\circ}$ $68^{\circ}$ and $50 \%$ increase in higher incidence angles. Therefore, PT increase may be less tolerated by patients with a low incidence angle. The perception of imbalance is intriguing. Among spine pelvic parameters, low incidence 


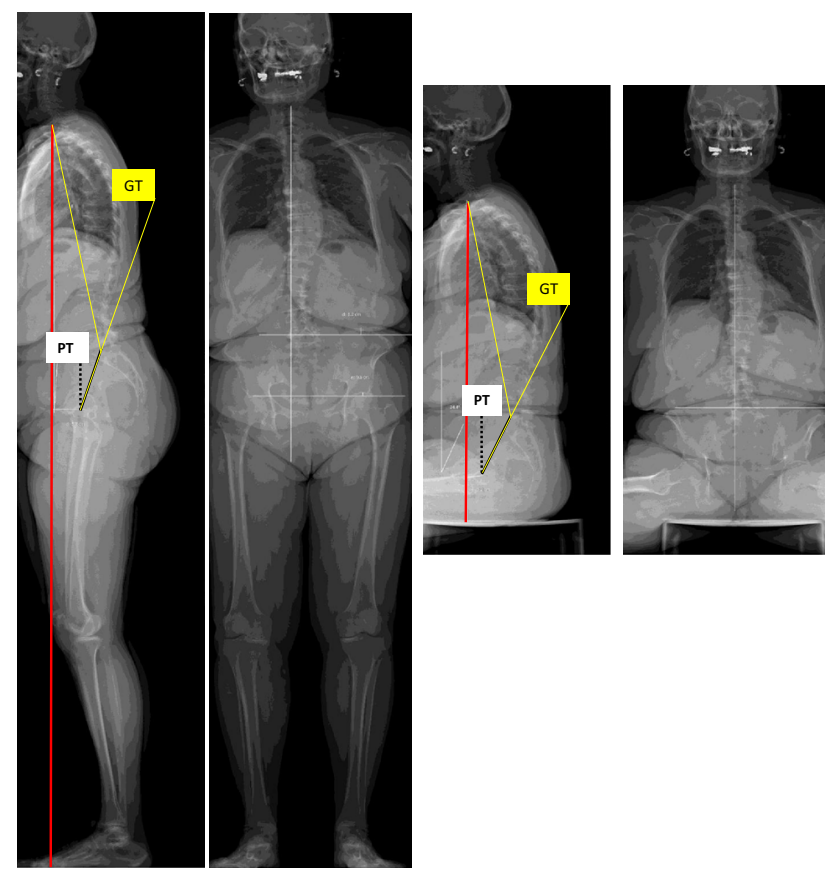

Fig. 10 Grade 3 patient in standing position: no adaptation of the lower limbs despite a C7 SVA $50 \mathrm{~mm}$ anterior to the femoral heads. The frontal imbalance could explain this limitation for the sagittal imbalance compensation. The comparison with sitting position (grade 2) shows some additional pelvic retroversion (moderate increase of PT and GT) angle, PT, and GT are the predominant factors. This is in accordance with the suggestions of previous literature [24]. The impact of lower limbs parameters is significant. Lower limbs issues as limb length discrepancy $>1 \mathrm{~cm}$, pelvic obliquity $>10^{\circ}$, varus $>6^{\circ}$, unilateral hip or knee flexum can act as add-ons to the perceived imbalance. The comparison of standing and sitting images can easily demonstrate the participation of the lower limbs in the postural imbalance.

Regarding the definition and the analysis of the compensatory mechanisms, this series points out a significant problem. The theory of the lower limbs adaptation is clear, logical, and qualitatively described in the literature [25]. But the reference values for the normal posture of lower limbs in standing position for this age category of patients is not well defined [26]. Several factors may interfere including the pelvic incidence angle [27] and the lower limbs anatomy to define the standard for FST and KFA [28]. According to the few published papers on this topic, we considered as an adaptive posture the cases with a mean knee flexum $>10^{\circ}$ and/or a mean FST $>15^{\circ}$.

In the global series of 294 imbalanced cases, the problem is basically a spine issue for 165 patients accounting for $56 \%$ of the series (117/172 patients with only spine problems and 48/122 cases with combined spine and lower
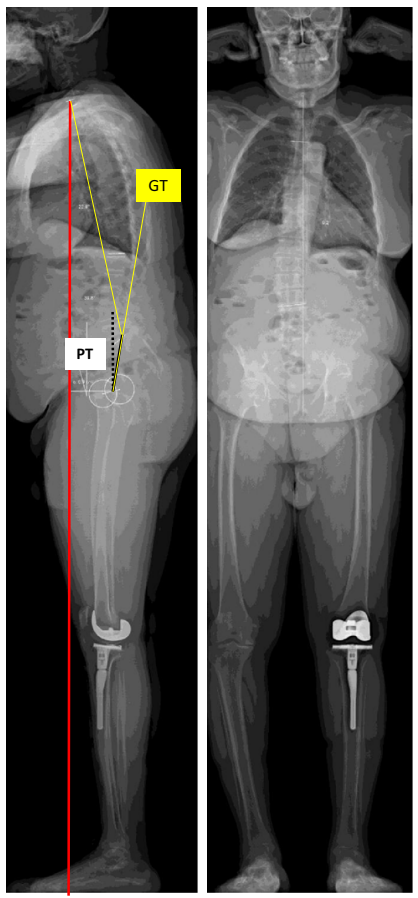

Fig. 11 Grade 3 patient in standing position. Despite an important sagittal imbalance (C7 SVA $69 \mathrm{~mm}$ anterior to the femoral heads) no adaptation of the lower limbs and the pelvic retroversion is not at its maximum in standing position. The comparison with sitting position demonstrates that an additional retroversion ability remains in

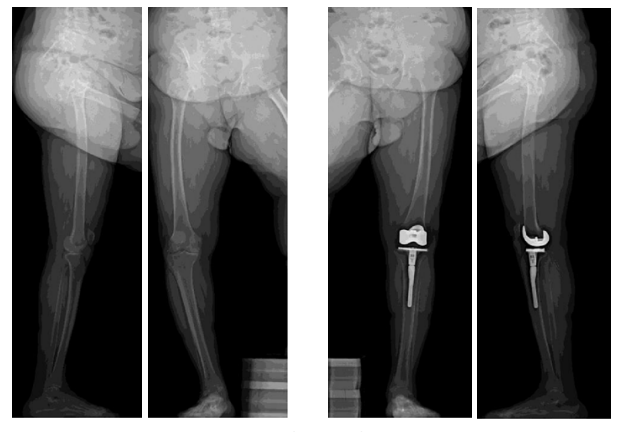

monopodal EOS knee test

standing position (PT variation). PT and GT increase when the patient moves to sitting position. The severe degradation of the right knee explains the impossibility for lower limbs compensation in standing position 

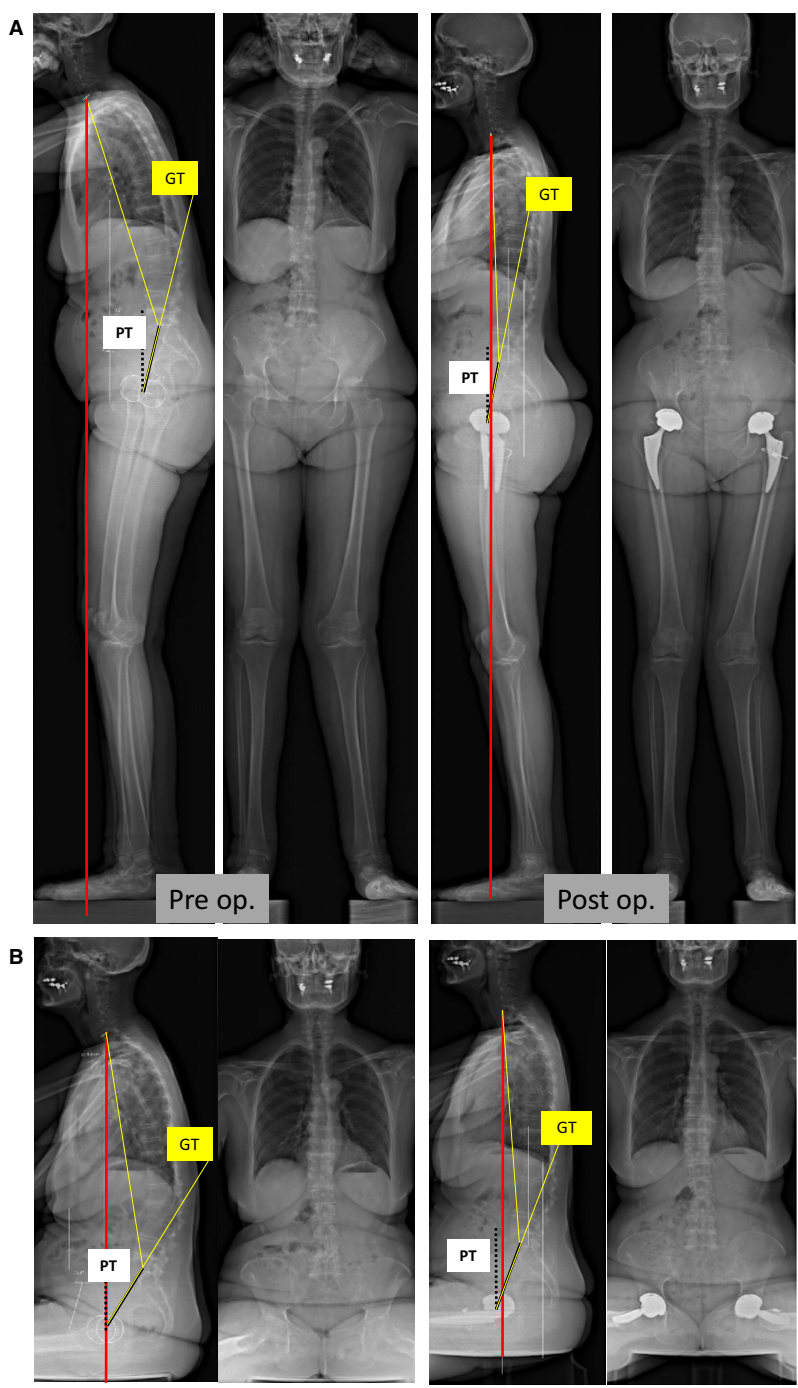

Fig. 12 Hip-spine syndrome (combination of a bilateral hip coxarthrosis and four levels of spinal stenosis: pre- and post-op evaluation standing and sitting). The hip replacement has induced significant modifications of sagittal alignment in both functional positions

limbs problems). But in combined spine and lower limbs problems, the clinician must also recognize hip-spine cases (24/122 patients in this series) and knee-spine cases (13/ 122 patients in this series). In some cases, (37/122 patients in this series) the anatomical and functional situations are more complex to determine whether the patient is facing a spine-hip or a hip-spine problem. The EOS dynamic tests can be useful in such cases (Figs. 12, 13) [27]. The comparison between standing and sitting postural situations is in accordance with previous data. The comfortable sitting position essentially corresponds to grade 2 . Interestingly, most of the patients keep an additional pelvic retroversion for the sitting position (mean PT variation $11^{\circ}$ ) despite the standing balance has already triggered a first step of pelvic extension and the adaptation of the lower limbs (Figs. 14, 15). This observation raises questions about the timing and distribution of the adaptation phenomena in the pelvic area and in the lower limbs. In the patients with low incidence angle $\left(<48^{\circ}\right)$ pelvic extension is rapidly spent and this starts the lower limbs adaptation. For the normal and high incidence angle cases, the pelvic extension reserve is larger but in most of cases the pelvic extension (retroversion) ability is not fully used in standing position (Fig. 16).

This study has limitations: It is only a snapshot of a current practice; the anatomical and functional evolution after surgery is not analyzed. But the description of this study highlights the importance of the lower limb evaluation not only as compensatory mechanism of the spinal problems but also as an individualized parameter with its own influence on the global balance analysis. Further studies are needed to optimize the analysis of hip-spine, knee-spine, spine-hip, or spine-knee syndromes. In this context the dynamic EOS tests to evaluate the extension ability of the whole body can be useful.

\section{Conclusion}

The understanding of sagittal alignment is now considered a key point in the evaluation of spinal degeneration as well as in hip or knee pathology as imbalance correlates with disability, pain, and suboptimal evolution after surgery $[23,29]$. Spinal imbalance causes the implementation of compensatory mechanisms including spine and lower limbs adaptation [24]. This study points out the magnitude of the imbalance problems in a current practice data base of spinal stenosis patients and the parasitic effects of lower limbs associated pathologies. Questions remain about the timing and distribution of the adaptation phenomena in the pelvic area and in the lower limbs. EOS biplane images provide innovative information about the spine, hip, and knee combined degenerations. Such a global view of the patient in functional standing and sitting positions provides new tools to analyze the spinal balance in lumbar stenosis patients and to optimize the surgical strategies. 
Fig. 13 Importance of the EOS extension test to decide the surgical strategy in case of sagittal imbalance. Patient with combined problems: adjacent levels stenosis above a previous lumbar fusion bilateral hips and knees degeneration. The hips problem is predominant according to clinical signs. The imbalance is grade 3 (a). The

(b) demonstrates that the sagittal imbalance is reducible. After bilateral THA (c). The imbalance is partially corrected (grade 2). The hips and knees flessum has disappeared hyperextension test
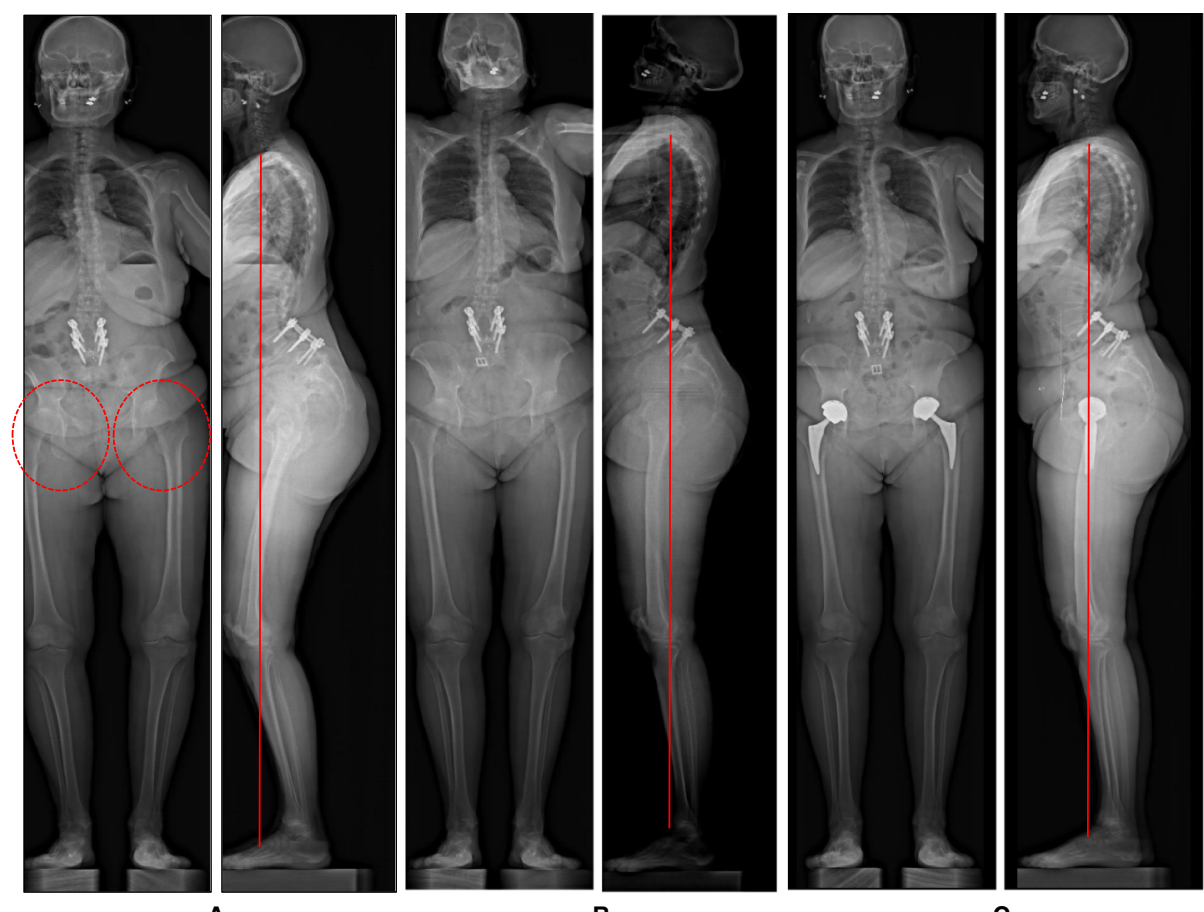

A

B
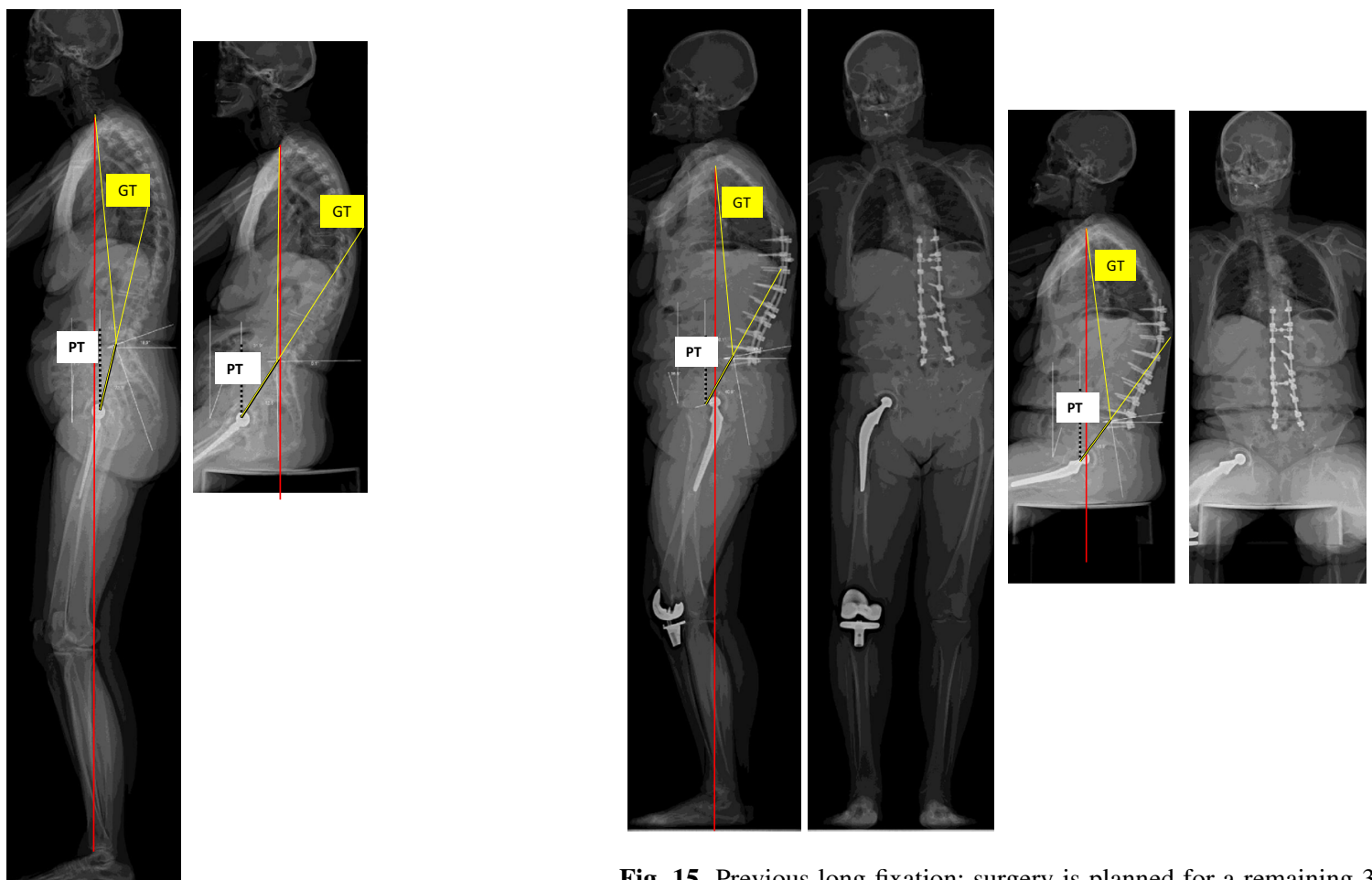

Fig. 14 Patient with low incidence angle $\left(33^{\circ}\right)$. Grade 2 standing grade 1 sitting. PT standing $14^{\circ}$, PT sitting $32^{\circ}$. The patient is mainly a spine user for sitting position (important modification of PT and GT)
Fig. 15 Previous long fixation; surgery is planned for a remaining 3 levels of stenosis. Comparison between standing (grade 3) and sitting (grade 2) shows the correction of the frontal pelvic obliquity due to lower limbs discrepancy (the hip and knee flexion are due to lengthening of the right side). The patient is mainly a hip user for sitting position (no significant modification of PT and GT) 


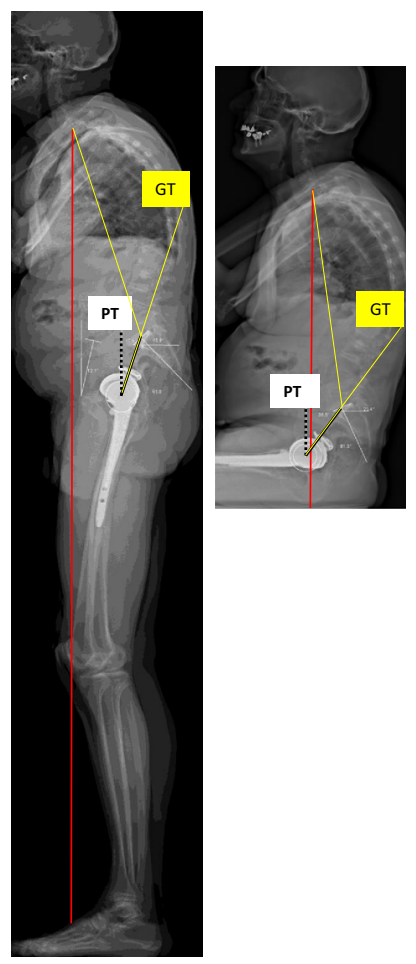

Fig. 16 High incidence angle $\left(62^{\circ}\right)$. Grade 3 in standing position, grade 2 in sitting position. PT $18^{\circ}$ standing, $36^{\circ}$ seated. GT increase in sitting position. The patient is a «mixed» hip and spine user for sitting position

\section{Compliance with ethical standards}

\section{Conflict of interest None.}

Ethical approval All procedures performed in studies involving human participants were in accordance with the ethical standards of the institutional and/or national research committee and with the 1964 Helsinki Declaration and its later amendments or comparable ethical standards.

Informed consent Informed consent was obtained from all individual participants included in the study.

\section{References}

1. Vialle R, Levassor N, Rillardon L et al (2005) Radiographic analysis of the sagittal alignment and balance of the spine in asymptomatic subjects. J Bone Joint Surg Am 87:260-267

2. Roussouly P, Gollogly S, Berthonnaud E, Dimnet J (2005) Classification of the normal variation in the sagittal alignment of the human lumbar spine and pelvis in the standing position. Spine (Phila Pa 1976) 30(3):346-353

3. Vaz G, Roussouly P, Berthonnaud E et al (2002) Sagittal morphology and equilibrium of pelvis and spine. Eur Spine $\mathbf{J}$ 11:80-88

4. Barrey C, Roussouly P, Le Huec JC, D’Acunzi G, Perrin G (2013) Compensatory mechanisms contributing to keep the sagittal balance of the spine. Eur Spine J 22(Suppl 6):S834-S841
5. Boulay C, Tardieu C, Hecquet J et al (2006) Sagittal alignment of spine and pelvis regulated by pelvic incidence: standard values and prediction of lordosis. Eur Spine J 15:415-422

6. Barrey C, Jund J, Noseda O et al (2007) Sagittal balance of the pelvis-spine complex and lumbar degenerative diseases. A comparative study about 85 cases. Eur Spine J 16:1459-1467

7. Funao H, Tsuji T, Hosogane N, Watanabe K, Ishii K, Nakamura M, Chiba K, Toyama Y, Matsumoto M (2012) Comparative study of spinopelvic sagittal alignment between patients with and without degenerative spondylolisthesis. Eur Spine J 21(11):2181-2187

8. Hammerberg EM, Wood KB (2003) Sagittal profile of the elderly. J Spinal Disord 16:44-50

9. Mac-Thiong JM, Roussouly P, Berthonnaud E, Guigui P (2011) Age- and sex-related variations in sagittal sacropelvic morphology and balance in asymptomatic adults. Eur Spine J 20(Suppl 5):572-577

10. Iyer S, Lenke LG, Nemani VM, Albert TJ, Sides BA, Metz LN, Cunningham ME, Kim HJ (2016) Variations in sagittal alignment parameters based on age: a prospective study of asymptomatic volunteers using full-body radiographs. Spine (Phila Pa 1976) [Epub ahead of print]

11. Murata Y, Takahashi K, Yamagata M, Hanaoka E, Moriya H (2003) The knee-spine syndrome. Association between lumbar lordosis and extension of the knee. J Bone Joint Surg (Br) 85-B:95-99

12. Ben-Galim P, Ben-Galim T, Rand N, Haim A, Hipp J, Dekel S, Floman Y (2007) Hip-spine syndrome: the effect of total hip replacement surgery on low back pain in severe osteoarthritis of the hip. Spine (Phila Pa 1976) 32(19):2099-2102

13. Obeid I, Hauger O, Aunoble S et al (2011) Global analysis of sagittal spinal alignment in major deformities: correlation between lack of lumbar lordosis and flexion of the knee. Eur Spine J 20(Suppl 5):681-685

14. Devin CJ, McCullough KA, Morris BJ, Yates AJ, Kang JD (2012) Hip-spine syndrome. J Am Acad Orthop Surg 20(7):434-442

15. Lee SM, Yoon MG, Moon MS et al (2013) Effect of correction of the contractured flexed osteoarthritic knee on the sagittal alignment by total replacement. Asian Spine J 7:204-211

16. Lee CS, Park SJ, Chung SS, Lee KH (2013) The effect of simulated knee flexion on sagittal spinal alignment: novel interpretation of spinopelvic alignment. Eur Spine J 22(5):1059-1065

17. Weng WJ, Wang WJ, Wu MD, Xu ZH, Xu LL, Qiu Y (2015) Characteristics of sagittal spine-pelvis-leg alignment in patients with severe hip osteoarthritis. Eur Spine J 24(6):1228-1236

18. Tauchi R, Imagama S, Muramoto A, Tsuboi M, Ishiguro N, Hasegawa Y (2015) Influence of spinal imbalance on knee osteoarthritis in community-living elderly adults. Nagoya J Med Sci 77(3):329-337

19. Wang WJ, Liu F, Zhu YW, Sun MH, Qiu Y, Weng WJ (2016) Sagittal alignment of the spine-pelvis-lower extremity axis in patients with severe knee osteoarthritis: a radiographic study. Bone Joint Res 5(5):198-205

20. Lazennec JY, Brusson A, Rousseau MA (2011) Hip-spine relations and sagittal balance clinical consequences. Eur Spine J 20(Suppl 5):686-698

21. Banno T, Togawa D, Arima H, Hasegawa T, Yamato $\mathrm{Y}$, Kobayashi S, Yasuda T, Oe S, Hoshino H, Matsuyama Y (2016) The cohort study for the determination of reference values for spinopelvic parameters (T1 pelvic angle and global tilt) in elderly volunteers. Eur Spine J. doi:10.1007/s00586-016-4411-x

22. Lazennec JY, Rousseau MA, Brusson A, Folinais D, Amel M, Clarke I, Pour AE (2015) Total hip prostheses in standing, sitting and squatting positions: an overview of our 8 years practice using the EOS imaging technology. Open Orthop J 9:26-44 
23. Roussouly P, Nnadi C (2010) Sagittal plane deformity: an overview of interpretation and management. Eur Spine J 9:1824-1836

24. Obeid I, Boissière L, Yilgor C, Larrieu D, Pellisé F, Alanay A, Acaroglu E, Perez-Grueso FJ, Kleinstück F, Vital JM, Bourghli A; European Spine Study Group, ESSG (2016) Global tilt: a single parameter incorporating spinal and pelvic sagittal parameters and least affected by patient positioning. Eur Spine J. doi:10.1007/s00586-016-4649-3

25. Le Huec JC, Charosky S, Barrey C, Rigal J, Aunoble S (2011) Sagittal imbalance cascade for simple degenerative spine and consequences: algorithm of decision for appropriate treatment. Eur Spine J 20(Suppl 5):699-703

26. Lazennec JY, Brusson A, Folinais D, Zhang A, Pour AE, Rousseau MA (2015) Measuring extension of the lumbar-pelvic- femoral complex with the EOS $^{\circledR}$ system. Eur J Orthop Surg Traumatol 25(6):1061-1068

27. Lazennec JY, Brusson A, Rousseau MA (2013) Lumbar-pelvicfemoral balance on sitting and standing lateral radiographs. Orthop Traumatol Surg Res 99(1 Suppl):S87-S103

28. Than P, Szuper K, Somoskeöy S, Warta V, Illés T (2012) Geometrical values of the normal and arthritic hip and knee detected with the EOS imaging system. Int Orthop 36(6):1291-1297. doi: $10.1007 / \mathrm{s} 00264$

29. Glassman SD, Bridwell K, Dimar JR, Horton W, Berven S, Schwab F (2005) The impact of positive sagittal balance in adult spinal deformity. Spine (Phila Pa 1976) 30(18):2024-2029 